\title{
OPEN Are heavy metals in urban garden soils linked to vulnerable populations? A case study from Guelph, Canada
}

\author{
Fernando Montaño-López \& Asim Biswas ${ }^{\bowtie}$
}

With increasing population, there is growing concern for food security in urban areas. Though, urban gardening has gained popularity, several studies have found higher concentrations of contaminants in urban soils, especially heavy metals, often at toxic levels, which pose a potential risk for human health. Moreover, heavy metal polluted sites have been strongly associated with areas populated by low-income families, newcomers and racial minorities. In this study, heavy metals in the soils of community gardens in the city of Guelph, ON were examined as a case study and their relationship with vulnerable populations. We analyzed soil samples at two depths for a range of heavy metals and characterized their spatial patterns to see if they were related to disadvantaged communities. We estimated the pollution levels using two index-based approaches and assessed their potential risk for human health, although concentrations of most heavy metals were below the limits established by Canadian regulations, metals like $\mathrm{Cd}, \mathrm{Pb}$, Se and $\mathrm{Zn}$ exhibited a mild degree of pollution, whereas As exhibited a severe degree. Their association with vulnerable populations were weak, but hotspots were mainly located in low-income areas. This case study provides scientific evidence that could help to expand our understanding around the interconnection between pollution and poverty/racial inequality. Also the importance of generating strategies for the protection of human health and sustainable soil management practices in urban areas where food for human consumption is grown.

While UN projections place more than $65 \%$ of the global population in urban centers by 2050 , healthy diets for many urban dwellers are constrained by limited incomes, rising food costs, and inequitable access to healthy and culturally appropriate foods; these are growing concerns in cities around the world ${ }^{1}$. Canadian cities are no exception ${ }^{2}$. Over the last few years, urban gardening has gained significant relevance due to its economic, social and cultural benefits; however, several studies in North America have shown that urban soils can have high concentrations of certain trace elements ${ }^{3}$. Since metals can enter the food chain from soil to groundwater or crops, urban soil contamination by heavy metals is of great concern in these areas as they may pose a potential risk for human health ${ }^{4}$.

High levels of contaminants in urban areas have been associated with site history and current land management practices ${ }^{5}$. Although there could be many sources that explain high heavy metal concentrations, some of the most common include: (1) deposition of small size particles, solid or liquid wastes; (2) incorporation of manufactured materials related to industry and (3) use of agrochemical inputs ${ }^{6}$. Soil test results and past factors can provide information to guide efforts to improve garden quality and protect the health of gardeners, their families, and other members in the community ${ }^{5}$.

Globally, there are more than 10 million sites of soil pollution reported, with $>50 \%$ of the sites contaminated with heavy metals and/or metalloids. It has been estimated that heavy metal pollution has a combined worldwide economic impact of more than US $\$ 10$ billion per year ${ }^{4}$. Despite extensive soil heavy metal pollution reports in urban areas, these studies have mainly focused on their correlation with land use history ${ }^{7-11}$. In addition, several studies have shown the negative impact of contaminated sites on the health of vulnerable populations ${ }^{12-16}$. These environmental hazards, therefore, are not randomly distributed. Low-income populations $s^{13}$, newcomers ${ }^{17,18}$ and racial minorities ${ }^{16,18}$ tend to be more exposed to environmental issues with potential health effects.

Previous studies reported that some Toronto residents face environmental exposure to heavy metals, especially those that belong to vulnerable communities ${ }^{17,19}$. Langlois et al. ${ }^{19}$ studied $\mathrm{Pb}$ levels in Toronto children, the 
heavy metal exposure was explained by past industrial activities in the area. Guelph, located in southern Ontario in Canada, constituted along with Toronto and other centers, an area of tremendous industrial concentration during the middle of the twentieth century ${ }^{20}$.

Guelph is a medium-sized city with a population of about 132,000 inhabitants. With a history of settlement as early as the 1820 s, the city has seen various uses of land over the years. In the past, Guelph was one of the most important manufacturing towns in South-Central Ontario with $48.8 \%$ of its population working for this sector by 1951, especially in iron, steel products, electrical apparatus and supplies ${ }^{20}$. Given background data on contamination due to land use across Southern Ontario, studying urban agricultural soils in Guelph was considered necessary. Making critical to develop a strategy to identify areas of high contamination and create alternatives to minimize the potential exposure of contaminants to disadvantaged neighborhoods.

Currently, there are a total of 28 community gardens used for raising vegetables. The soils of these gardens are rarely analyzed and yet, they could be contaminated with heavy metals. For example, McKeague et al. ${ }^{21}$ studied the level of minor elements in Canadian soils, finding $\mathrm{Pb}$ concentrations ranging from 12 to $71 \mathrm{ppm}$ in sites near the city. While soil contaminants pose a risk to human health, the contaminated soils are often found in older and/or vulnerable neighborhoods located near the source of contaminants or which were previously zoned as industrial areas ${ }^{18,22}$. Little work has been done on mapping the spatial distribution of soil contaminants in urban agricultural settings and their association with vulnerable populations.. The present study was carried out on a regional scale to analyze the spatial pattern of heavy metal pollution in community gardens and better understand its relationship with disproportionate sociospatial bias that puts vulnerable populations in risk. Although there might not be a single explanation of these situations, these risks tend to cluster with one another, creating a long-term cumulative effect on environmental injustice and health disparities ${ }^{23}$.

\section{Materials and methods}

Study area and soil sampling. The study area, the city of Guelph, is in the province of Ontario, Canada. It is one of the fastest growing cities in Ontario with a very low unemployment rate and it attracts diverse populations. The urban area covers about $87 \mathrm{~km}^{2}$ with a population density of 1511 per $\mathrm{km}^{2}$. Guelph experiences cold winters and warm, humid summers with moderately high rainfall and snowfall. The city is situated on several drumlins of deglaciated landscapes.

Due to its population diversity, to date there are 28 active community gardens in the city. In 2018 , there were only 22 community gardens, which shows the increasing interest in growing food locally. A total of 40 surface (0-15 cm depth) and subsurface (15-30 cm depth) soil samples were collected with a hand auger from 20 participating community gardens (Fig. 1; two garden coordinators were inaccessible to collect soil samples) during the summer 2018. Each soil sample comprised a composite sample of seven subsamples taken across the community gardens. Samples were mixed thoroughly to make representative samples, sealed in polyethylene bags and taken to the laboratory for further analysis. In addition to the 40 composite samples, two soil cores of $5 \mathrm{~cm}$ tall and $5.7 \mathrm{~cm}$ diameter (volume- $127.587 \mathrm{~cm}^{3}$ ) were collected from each community garden for moisture and bulk density analysis. Soil cores were collected from 5 to 10 and $20-25 \mathrm{~cm}$ depth representing the sampling depths.

Physical and chemical analysis. Soil samples were air-dried, sieved through a 2-mm sieve and ground with a mortar and pestle to achieve a homogenous sample. Soil $\mathrm{pH}$ and EC were measured in distilled water, using a pH meter (Fisher Scientific, Model accumet AE150) and a digital conductivity cell (Fisher Scientific, Model accumet XL600), respectively, with a soil: solution ratio of 1:2. Soil bulk density was determined from previously collected undisturbed cores as mass per volume of oven dried soil. Soil texture was determined using the hydrometer method, separating very coarse sand, coarse sand, and medium sand with stacked sieves. As the content of organic matter was high in most of the samples, 25-30 g of soil were treated with hydrogen peroxide (30\%) for OM removal, then left in Calgon solution (5\%) overnight.

Organic matter was measured using the loss on ignition (LOI) method. Finely ground soil, which could pass through a $75 \mu \mathrm{m}$ sieve was weighed $(\cong 4 \mathrm{~g})$ into porcelain boats. Samples were placed in a preheated $550{ }^{\circ} \mathrm{C}$ muffle furnace for $6 \mathrm{~h}$. After $6 \mathrm{~h}$, the muffle furnace was turned off and left to cool overnight. The next day, the porcelain boats were weighted, full and empty, and OM was calculated based on the weight difference of the sample.

Soil moisture was measured using the gravimetric method. Soil samples from two different depths (5-10 and $20-25 \mathrm{~cm}$ ) were placed immediately in a polyethylene sealed bag. The sample was weighed as received in the laboratory and again after drying in an oven for $24 \mathrm{~h}$ at $105^{\circ} \mathrm{C}$. Heavy metal concentration was measured in the Soil and Water Testing Laboratory at McGill University. Previously processed and finely ground $0.160 \mathrm{~g}$ of soil sample was mixed with $2 \mathrm{~mL}$ of $\mathrm{HNO}_{3}(70 \%)$ and let stand overnight. Then, on dry block, samples were slowly heated to $120^{\circ} \mathrm{C}$ for $5 \mathrm{~h}$. Once cooled to room temperature, samples were transferred to polypropylene tubes for a final volume of $50 \mathrm{~mL}$ using nanopure water and mixed thoroughly. Next day, samples were diluted to $20 \times$ and $\mathrm{HNO}_{3}$ was added to a final $1 \% \mathrm{v} / \mathrm{v}$ nitric acid concentration. Total concentration was measured on a Varian ICP-MS model 820 MS (Analytik-Jena, Germany). For quality assurance and quality control (found in Supplementary Material), blanks were run every 12 samples to avoid background noise impact, parallel replication of samples were simultaneously determined, and standard reference materials were provided by Environment Canada, a national regulatory body.

Statistical data and analysis. We collected sociodemographic data from the 2016 Census done by Statistics Canada. This data provided information about median total income of households, percentage of immigrant population and percentage of visible minorities in a census tract level. All data analyses were performed using Microsoft Office Excel 2016. GIS-based approach was used to characterize the spatial distribution of heavy metals at the regional scale. The spatial distribution using inverse distance weighted (IDW) was performed using 


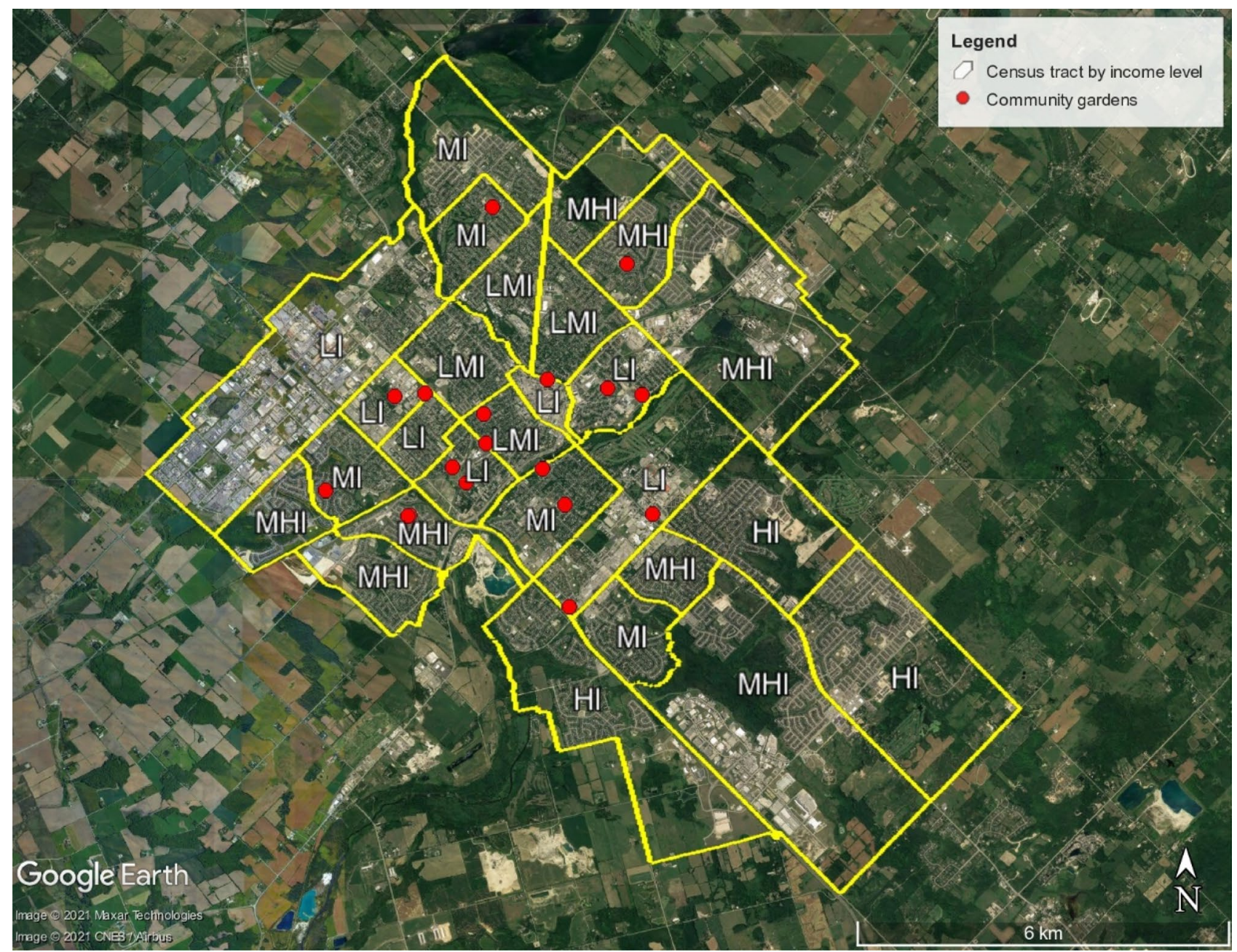

Figure 1. Map of the study area and sampling points. The map was prepared by using the "Places" tool in Google Earth Pro (https://www.google.com/earth/).

ESRI ArcGIS 10.4. To associate heavy metal pollution with sociodemographic data, we carried out Pearson's product-moment correlation. For this, we estimated the centroid from the spatial distribution maps of metals with mild to severe degree of pollution to obtain a representative value for every census tract area. These areas are divided in low (LI), low to middle (LMI), middle (MI), middle to high (MHI) and high income (HI).

\section{Results and discussion}

Physico-chemical parameters. The soil properties, including $\mathrm{pH}, \mathrm{EC}$, texture, and organic matter (OM) content varied from garden to garden and across depths. Values of $\mathrm{pH}$ ranged from 7.31 to 8.03 with a mean value of 7.73. These suggested neutral conditions tended to vary to slightly alkaline conditions for all soil samples. Similar pH characteristics (near neutral, 6.5-7.5) in urban gardens and the unavailability of many metals for ready uptake into plant tissues under these conditions have been described by the Cornell Waste Management Institute ${ }^{24}$. This is probably the most important factor controlling the uptake of heavy metals ${ }^{25}$. Soil EC exhibited a large range. The minimum value was $366.322 \mu \mathrm{S} \mathrm{cm}^{-1}$ and the maximum was $2713.69 \mu \mathrm{S} \mathrm{cm}-1$, with the mean value of $822.11 \mu \mathrm{S} \mathrm{cm}^{-1}$, classifying most samples as nonsaline according to Boulding ${ }^{26}$.

For particle size distribution, sand size fraction was the highest, followed by silt and clay. Guelph soils have been described as predominantly loams with some small areas of sandy loam. The higher sand content in these soils may be due to the influence of the outwash sands which surround them ${ }^{27}$.

The OM content ranged from 5.62 to $22 \%$ with an average value $11.22 \%$. According to Impellitteri et al. ${ }^{28}$, the complex interactions between heavy metals and soil organic matter result in changes in solubility, mobility and bioavailability of these elements. Generally, the solid phase organic matter is associated with retention, decreased mobility and reduced bioavailability of trace metals.

Bulk density and moisture were determined for the soil samples collected from 5 to 10 and $20-25 \mathrm{~cm}$ depth. Bulk density values fluctuated between 0.644 and $1.14 \mathrm{~g} \mathrm{~cm}^{-3}$. Moisture ranged from 8.13 to $48.34 \%$ with a mean value of $22.91 \%$. 


\begin{tabular}{|l|l|l|l|l|l|l|l|l|}
\hline Variable & Zn & Rb & Sr & Cd & Ce & Pb & As & Se \\
\hline Mean & 196.04 & 13.00 & 52.85 & 0.74 & 32.66 & 43.66 & 4.68 & 0.92 \\
\hline SD & 138.26 & 2.22 & 23.92 & 0.35 & 4.79 & 38.10 & 10.39 & 0.85 \\
\hline Median & 132.21 & 13.06 & 51.79 & 0.62 & 31.48 & 28.84 & 2.22 & 0.64 \\
\hline Minimum & 96.58 & 8.81 & 18.17 & 0.38 & 22.97 & 15.74 & ND $^{*}$ & ND $^{*}$ \\
\hline Maximum & 502.91 & 17.44 & 96.00 & 1.84 & 41.22 & 151.02 & 47.41 & 3.00 \\
\hline CV & 70.53 & 17.06 & 45.27 & 46.81 & 14.67 & 87.28 & 222.21 & 92.24 \\
\hline CCME limits & 250 & - & - & 1.4 & - & 70 & 12 & 1 \\
\hline
\end{tabular}

Table 1. Descriptive statistics of the soil heavy metal concentrations at $0-15 \mathrm{~cm}$ in Guelph community gardens (in ppm). ${ }^{\star} N D$ non-detectable.

\begin{tabular}{|l|l|l|l|l|l|l|l|l|}
\hline Variable & Zn & Rb & Sr & Cd & Ce & Pb & As & Se \\
\hline Mean & 184.85 & 12.90 & 55.56 & 0.71 & 34.75 & 38.56 & 4.22 & 0.97 \\
\hline SD & 144.20 & 2.19 & 29.33 & 0.26 & 6.84 & 30.01 & 7.15 & 0.82 \\
\hline Median & 124.96 & 13.05 & 47.28 & 0.63 & 34.19 & 26.02 & 2.82 & 0.64 \\
\hline Minimum & 81.59 & 8.82 & 16.83 & 0.38 & 23.08 & 14.47 & ND $^{*}$ & ND $^{*}$ \\
\hline Maximum & 546.67 & 16.74 & 136.04 & 1.23 & 52.50 & 124.41 & 31.57 & 3.11 \\
\hline CV & 78.01 & 16.97 & 52.78 & 35.93 & 19.68 & 77.82 & 169.71 & 84.70 \\
\hline CCME limits & 250 & - & - & 1.4 & - & 70 & 12 & 1 \\
\hline
\end{tabular}

Table 2. Descriptive statistics of the soil heavy metal concentrations at $15-30 \mathrm{~cm}$ in Guelph community gardens (in ppm). ${ }^{\star} N D$ non-detectable.

Sociodemographic of Guelph and community gardens. An initial assessment of sociodemographic information made available by Statistics Canada $\left(2017,{ }^{29}\right)$, shows that Guelph is a city with around 132,000 inhabitants in which the average household size is 2.5 people. The median total income of households is 77,984 $\mathrm{CAD}$, an amount below the national median (81,347 CAD). The total visible minority population is around 24,500 people, defined as "persons, other than Aboriginal peoples, who are non-Caucasian in race or non-white in colour". And the immigrant population is around 28,000 people, this category is defined as "persons who are, or who have ever been, landed immigrants or permanent residents".

At the census tract level, the median household income ranges from 45,517 to 112,085 CAD. When this range is divided in five proportional categories of income, $50 \%$ of the gardens are located in areas with the lowest income. This proportion could indicate the importance of urban agricultural production for low-income neighborhoods. In terms of immigrant population cultivating food in the city, data shows the top two categorized areas inhabited with more immigrant population hold $27 \%$ of gardens, however the categories with less immigrant population hold $66 \%$ of the community gardens. Regarding the proportion of visible minorities, the areas with less percentage of visible minorities have $55 \%$ of the total gardens, while the areas with more visible minorities have $38 \%$ of the gardens.

Heavy metals in community gardens. The descriptive statistics of metal concentrations at $0-15$ and 15-30 cm depths are presented in Tables 1 and 2, respectively. Concentration of heavy metals varied among the community gardens. Mean concentrations of $\mathrm{Co}, \mathrm{Ni}, \mathrm{Cu}, \mathrm{Ba}$ and $\mathrm{Cr}$ were below the limits for garden soils according to the Canadian Council of Ministers of the Environment $\left(\mathrm{CCME}^{30}\right)$ soil quality guideline for agricultural land use that were established to protect agricultural production and to maintain human health. However, some sites showed high levels of contamination for certain elements. For Zn, 17.5\% of the samples exceeded the CCME limits. Similarly, for Pb, 15\% of the sites sampled showed concentrations above the limits for food production established by the CCME, while for As, two samples showed higher concentrations than permissible limits and for Cd, only one sample surpassed the limits. However, for Se, $45 \%$ of the study sites showed concentrations above $1 \mathrm{ppm}$. A wide range of concentration of these metals could point to an anthropogenic source of contamination.

Different concentrations of minor elements were also found in the studied community gardens including Cerium, Strontium and Rubidium. No information about CCME limits is available for these metals; this may be due to their unknown influence. According to Ramos et al. ${ }^{31}$, current information is not enough to determine the safe levels of exposure in humans. However, higher concentrations of these elements in this study pose a question for assessment of these metal's influence and inclusion in the CCME guideline. Data on background levels is essential for assessment of the degree of soil contamination as the elements can be part of the nutritional chain form soil to plants to animals, including humans. 

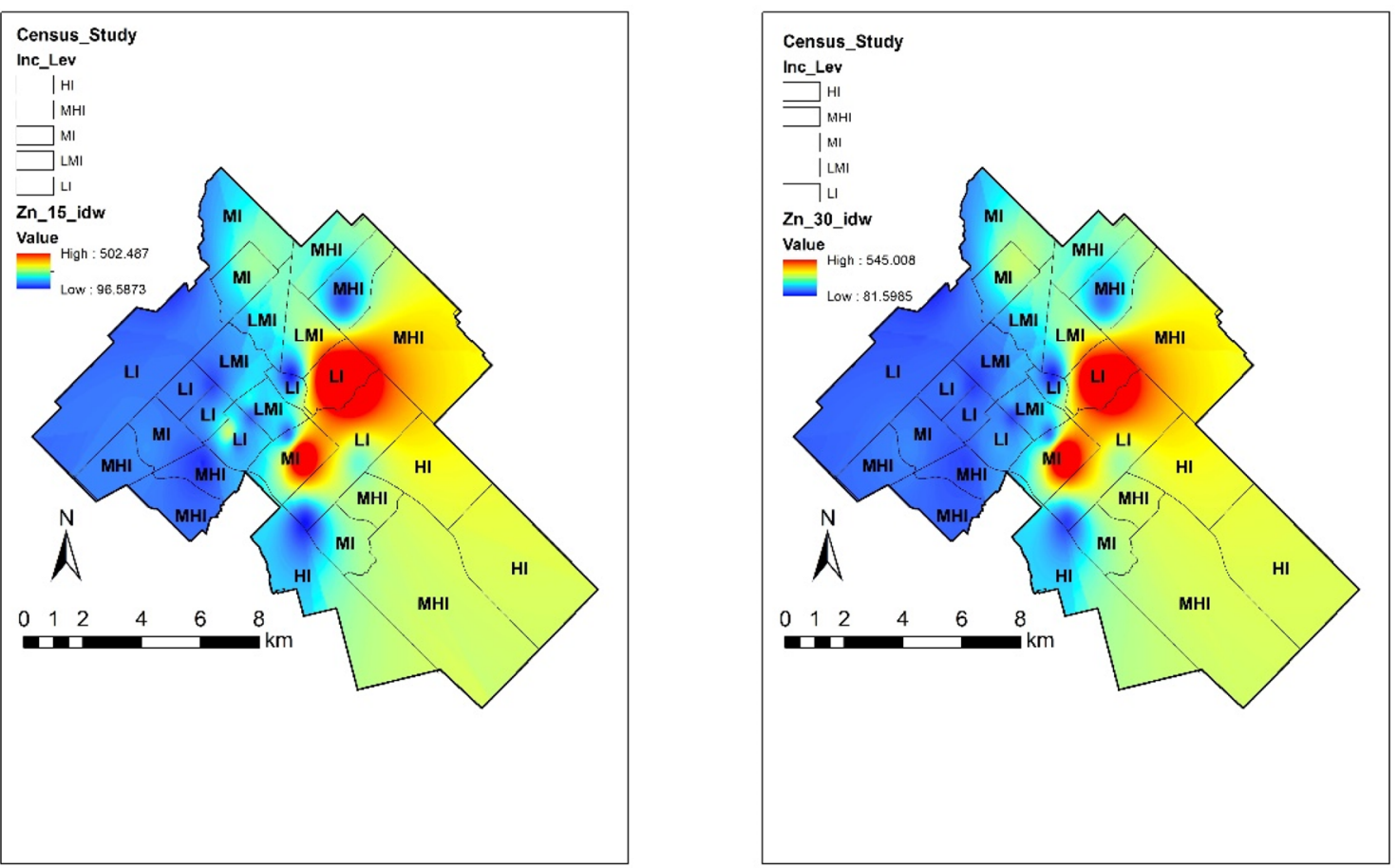

Figure 2. Spatial distribution of $\mathrm{Zn}$ at $0-15$ and $15-30 \mathrm{~cm}$ depth in urban gardens of Guelph in relation with income level. The map was prepared by using the "Geostatistical Analyst" tool in ArcGIS 10.4 (https://desktop. arcgis.com/en/).

Potential public health risks in vulnerable populations. Zinc. Concentrations of $\mathrm{Zn}$ in community gardens in Guelph variated from 81.59 to $546.67 \mathrm{ppm}$ at two depths, while the limit established by the CCME is $250 \mathrm{ppm}$. High concentrations of $\mathrm{Zn}$ were found in the central downtown area of the city. This region is characterized by past intense industrial activity and may contribute to the high heavy metal concentration of the soils. Besides the anthropogenic contributions, mineral deposits of sphalerite (a $\mathrm{Zn}$ rich mineral) have been found across the central part of Guelph ${ }^{32}$.

The behaviour of this metal in surface soils in relationship with the sociodemographic data shows that it is weakly associated with low income $(\mathrm{r}=0.12)$, and a weak negative association with both percentage of immigrants $(r=-0.32)$ and percentage of minorities $(r=-0.28)$. In subsurface soils the correlations with low-income neighborhoods $(r=0.16)$, immigrant $(r=-0.32)$ and minority population $(r=-0.27)$ behaved similarly. The spatial distribution of this element by income level of census tract areas is found in Fig. 2.

According to Alloway ${ }^{6}, \mathrm{Zn}$ is naturally present in all soils with typical background concentrations of 10-100 $\mathrm{mg} \mathrm{kg}{ }^{-1}$ or ppm. Human activities have enriched top soils and $\mathrm{Zn}$ toxic soils are less widespread than deficient ones. $\mathrm{Zn}$ contaminated soils are unlikely to pose a risk to humans as the phytotoxic effects may limit transfer of excessive $\mathrm{Zn}$ to the human food chain. Therefore, risk assessment of $\mathrm{Zn}$ contaminated soils focuses on its ecotoxicological effects on soil organisms. However, the long-term exposure for residents in areas with $\mathrm{Zn}$ concentrations above the CCME limits $\mathrm{Zn}$ can experience negative impact on organs like the brain, causing lethargy and focal neuronal deficits; in the respiratory tract, it can cause respiratory disorder after inhalation of $\mathrm{Zn}$ smoke and metal fume fever; and in the gastrointestinal tract, it may cause nausea/vomiting, epigastric pain and diarrhea. It can also pose an elevated risk of prostate cancer ${ }^{33}$.

Cadmium. Cd is a non-essential metal that is naturally present in all soils as a divalent cation at concentrations typically ranging between 0.1 and $1.0 \mathrm{ppm}$. The presence of $\mathrm{Cd}$ is unlikely to affect the chemistry of soil ${ }^{6}$. However, given its pronounced toxicity, Cd can affect ecosystem functions at trace levels. Additionally, the toxicity of $\mathrm{Cd}$ in soil is persistent, since its residence time exceeds decades and its bioavailability does not decrease over time ${ }^{34}$. In this study, the concentration of $\mathrm{Cd}$ was low compared to the limits established by the CCME except for one garden with a concentration of $1.4 \mathrm{ppm}$. However, monitoring of this metal is essential for future management practices. Figure 3 illustrates the spatial distribution of Cd in Guelph. Cd hotspots were detected in low-income areas of the downtown area of Guelph, in which higher levels of Cd may be ascribed to anthropogenic activities. Previous studies have shown that $\mathrm{Cd}$ concentrations in soil are closely related to foundry and smelting activities ${ }^{35,36}$, these types of industries played an important role in sites near the affected zone. Pearson correlation coefficients showed that $\mathrm{Cd}$ is not correlated with income levels in surface $(\mathrm{r}=-0.009)$ and subsurface (0.035) soils. While also showing weak negative correlations with immigrant $(r=-0.39$ and $r=-0.23)$ and visible minority populations $(\mathrm{r}=-0.35$ and $\mathrm{r}=-0.20)$ in both depths.

However, in the area with high Cd concentration, low-income dwellers can face negative health effects associated with $\mathrm{Cd}$ exposure. According to the $\mathrm{ATSDR}^{37}$, eating food or drinking water with very high Cd levels severely 

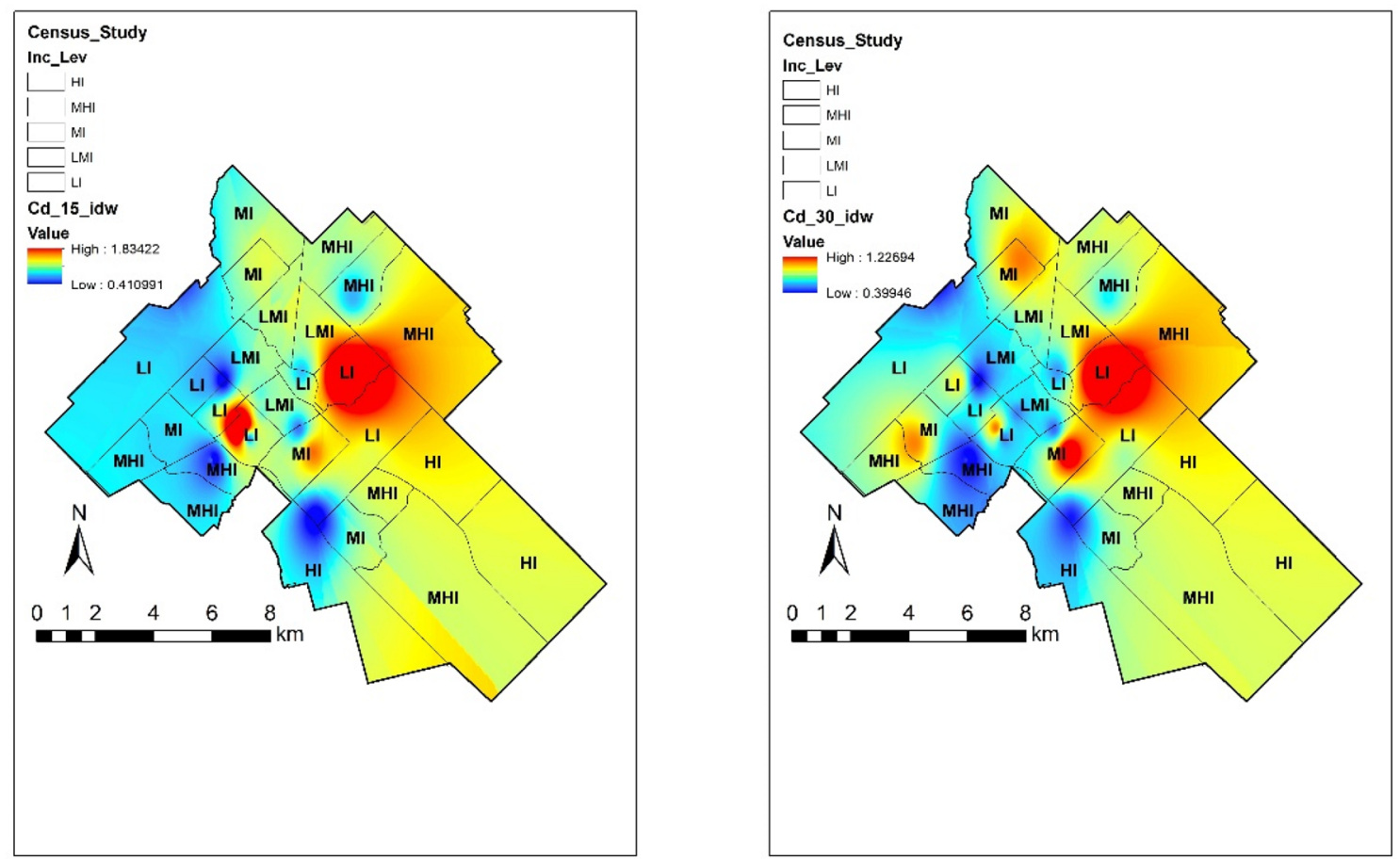

Figure 3. Cd content in 0-15 and 15-30 cm depth with varying income levels. The map was prepared by using the "Geostatistical Analyst" tool in ArcGIS 10.4 (https://desktop.arcgis.com/en/).

irritates the stomach, leading to vomiting and diarrhoea, and sometimes even death. Eating lower levels of Cd over a long period of time can lead to a build-up of $\mathrm{Cd}$ in the kidneys and exposure to low levels of $\mathrm{Cd}$ over a long time can also cause bones to become fragile and break easily. It has also been determined that $\mathrm{Cd}$ and its compounds are human carcinogens.

Lead. According to Alloway ${ }^{6}, \mathrm{~Pb}$ exists predominantly in the +2 oxidation state and it may remain bioavailable for a long period of time. The chemical behaviour of $\mathrm{Pb}$ in soil depends very much on the organic matter content. $\mathrm{Pb}$ is strongly adsorbed on organic matter at $\mathrm{pH} 5$ and above ${ }^{24}$. Although most of the community gardens showed relatively low concentrations of $\mathrm{Pb}$, around $15 \%$ exceeded the limits established in Canada with the highest concentration of $151.02 \mathrm{ppm}$ at the top $15 \mathrm{~cm}$ soil. Figure 4 shows different concentrations of $\mathrm{Pb}$ across Guelph by income level in two different depths. The most heavily polluted sites found in the northeast and downtown part of the study area were associated with a site history that includes important industrial activity, mineral deposits of galena ( $\mathrm{Pb}$ mineral) and over a century of agricultural activities which could be associated with the use of agrochemicals containing $\mathrm{Pb}$.

Similar to previous metals mentioned, correlation coefficients showed very weak association with low income $(r=0.03$ and $r=0.04)$ and negative weak link with immigrant $(r=-0.39$ and $r=-0.35)$ and visible minority $(r=-0.37$ and $r=-0.31)$ populations at both depths sampled. Although there was a very low association with vulnerable populations, an important hotspot is located within a low-income neighbourhood. Special attention should be paid in that zone to small children due to their vulnerability to $\mathrm{Pb}$ toxic consequences. These consequences may cause negative lifelong effects on their nervous system. Also, long-term exposure of $\mathrm{Pb}$ for adults, produces risk of high blood pressure and kidney damage. Finally, complications during pregnancy can involve the mother's and baby's health ${ }^{38}$.

Arsenic. As is ubiquitous in nature, occurring in most soils and rocks at detectable quantities. As exists in more than one oxidation state; and bonds with sulphur, organic matter and carbon more readily, and undergoes biological transformations resulting in volatilization from soil ${ }^{6,39}$. There was only one garden that surpassed 12 ppm of permissible limit set by CCME. Moreover, these concentrations were 31.57 and $47.41 \mathrm{ppm}$, much higher than the set limit indicating a possible toxic area within the city. Figure 5 shows the spatial distribution of As in Guelph. The elevated concentration in the northeast part of the region could have been caused by the past use of agrochemicals; however, this elucidation requires further investigation.

As distribution in relation with vulnerable populations showed negative and weak correlation for all sociodemographic variables. Pearson correlation values show that there is not a strong relationship with low income $(\mathrm{r}=-0.26, \mathrm{r}=-0.05)$, immigrant communities $(\mathrm{r}=-0.31$ and $\mathrm{r}=-0.38)$ and visible minorities $(\mathrm{r}=-0.38$ and $r=-0.43$ ) in the two different depths of this study. Even though only one site was heavily polluted with As, constant monitoring of this should be in place. The potential risks associated for residents of that area include the decrease in production of white and red blood cells. This can lead to damages in the circulatory and nervous system. Skin associated problems (like redness and swelling) may occur when direct dermal contact with As 

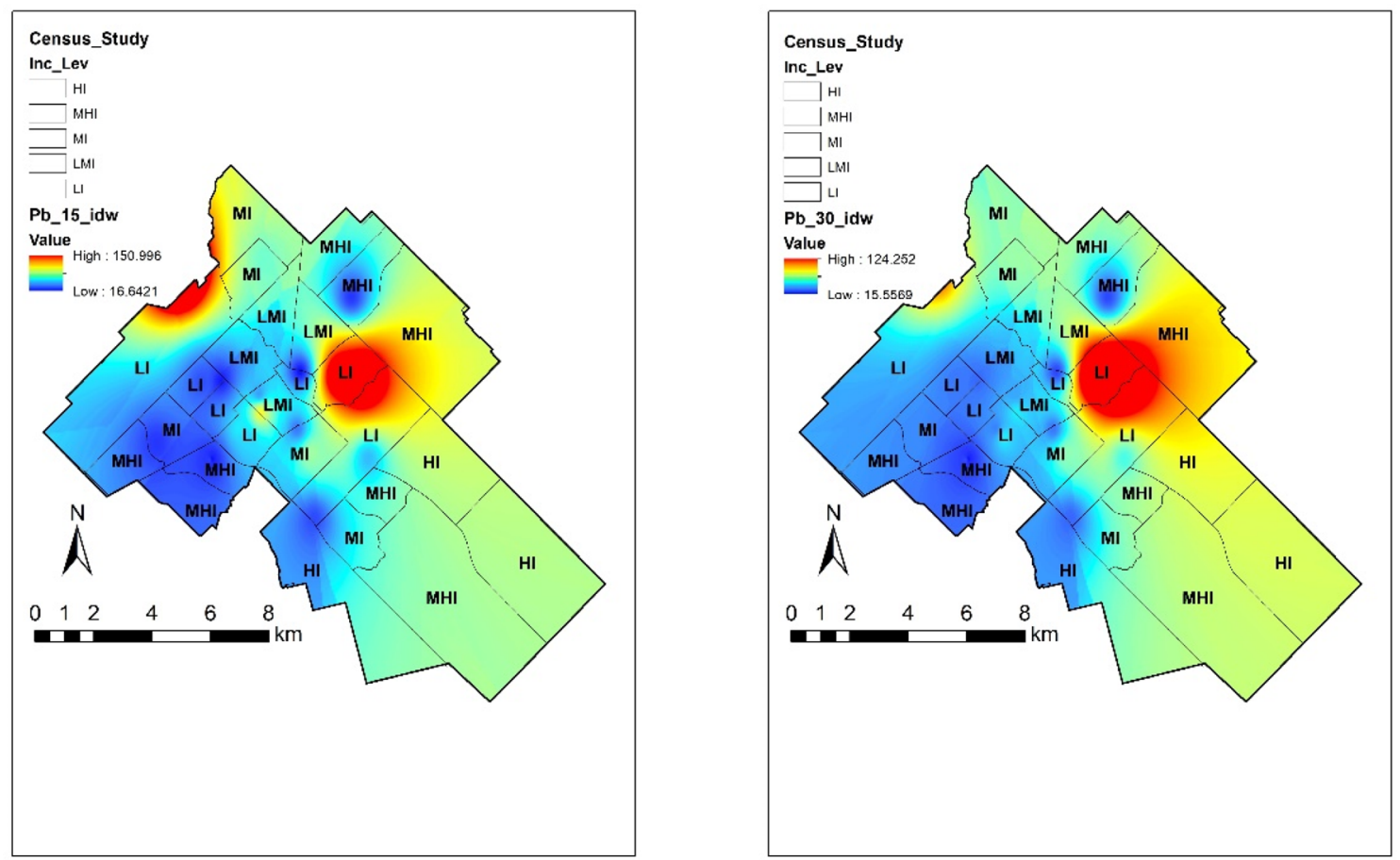

Figure 4. Concentration of $\mathrm{Pb}$ around the city in relation with income. The map was prepared by using the "Geostatistical Analyst" tool in ArcGIS 10.4 (https://desktop.arcgis.com/en/).
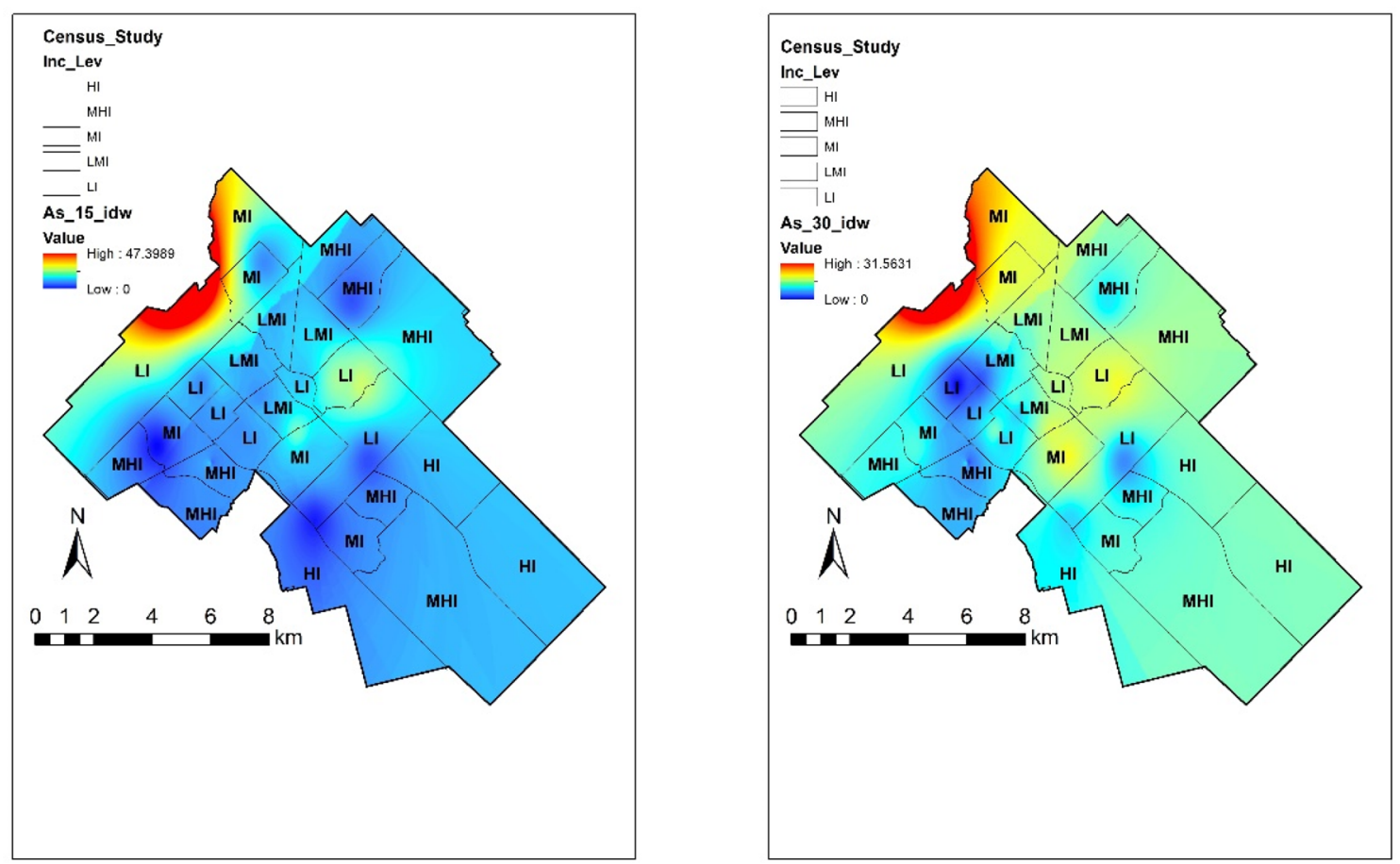

Figure 5. As concentrations across Guelph in two different depths and its association with low-income communities. The map was prepared by using the "Geostatistical Analyst" tool in ArcGIS 10.4 (https://desktop. arcgis.com/en/).

is produced. It is well-known that inorganic As is carcinogenic to humans, while organic As compounds show lower toxicity to humans as compared to its inorganic form ${ }^{40}$.

Selenium. Se in soil is found in different forms and oxidation states. Typical levels of Se in soil range from 0.01 to $2 \mathrm{ppm}$. However, due to Se partitioning on its solid phase, concentration values do not portray the effects 

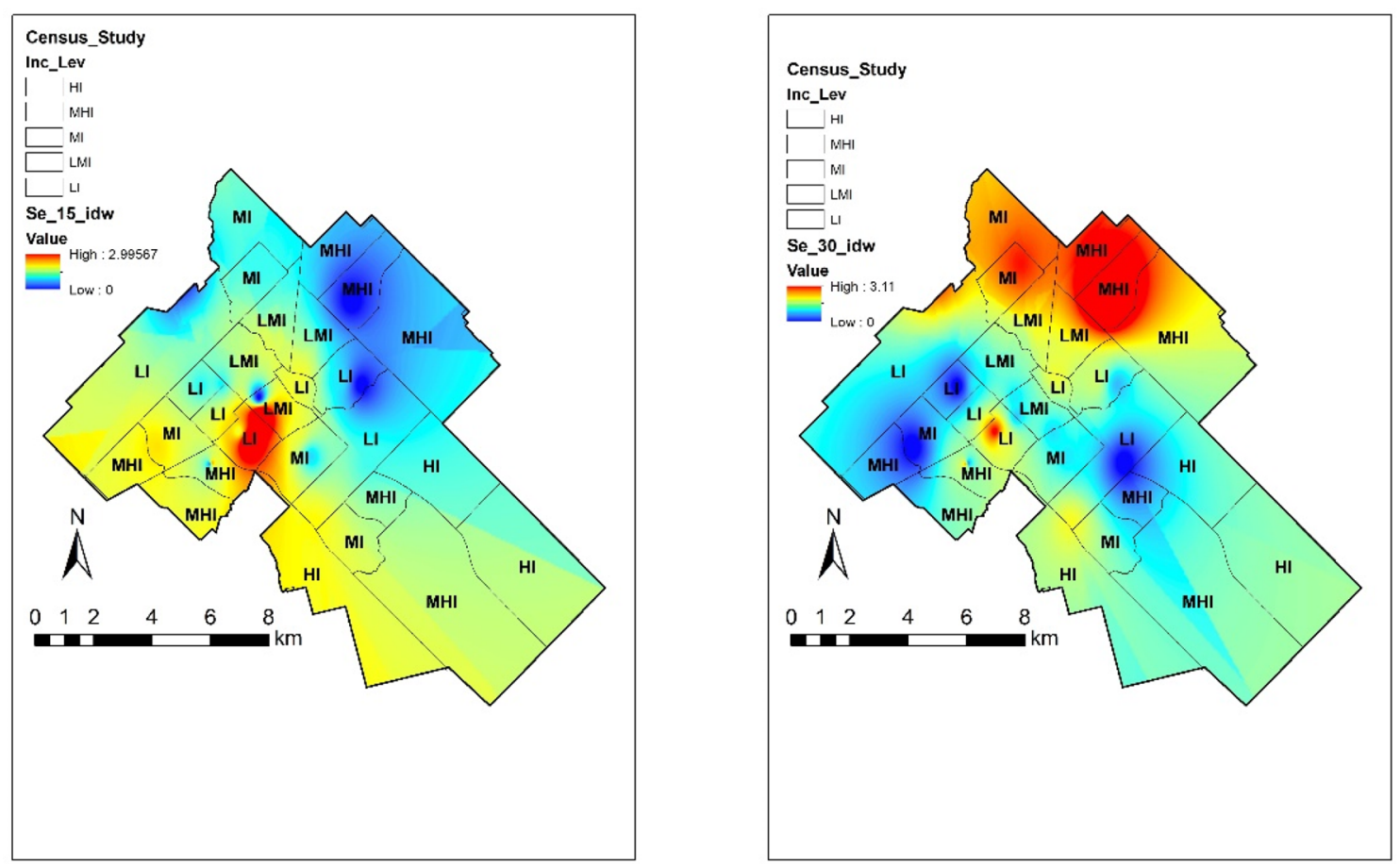

Figure 6. Spatial distribution of Se in Guelph in the $0-15$ and $15-30 \mathrm{~cm}$ depth with varying income conditions. The map was prepared by using the "Geostatistical Analyst" tool in ArcGIS 10.4 (https://desktop.arcgis.com/ en/).

of this element on the environment. Increasing amounts of Se in the environment have been recorded and attributed to human and natural activities ${ }^{41}$. In almost half of the samples, Se showed higher concentrations than the permissible limit of CCME, showing a more threatening distribution in Guelph. Figure 6 shows these concentrations in the city in association with low-income areas. Pearson correlation coefficients show different patterns in both depths. In surface soils, low income had a negative weak association $(r=-0.21)$ while immigrant $(\mathrm{r}=0.06)$ and minorities $(\mathrm{r}=0.06)$ had very weak relation. For subsurface soils, low-income had a positive weak correlation and immigrant communities $(r=-0.42)$ and visible minorities $(r=-0.43)$ in the area showed a weak negative correlation. The spatial distribution of Se presented different patterns, high levels in surface soil were found in the central area while hotspots in subsurface soil were found in the northeast of Guelph. These areas are linked to previous industrial activities such as coal combustion, oil processing and smelting, known as anthropogenic sources of $\mathrm{Se}^{41}$.

Se behaviour in the environment is mainly dependent on its concentration level and speciation. The latter, mostly controlled by redox potential and $\mathrm{pH}$ which regulates its mobility in soil ${ }^{41}$. Attention should be paid in those areas with concentrations above the CCME limits, which could face "selenosis", a condition that results from high Se level in blood, its symptoms include irritability, hair loss, dermal and neurological damage ${ }^{42}$.

Assessment of pollution in community gardens. The single pollution index can be used to evaluate the degree of heavy metal pollution in soil. This method measures pollution by a single element and refers to the ratio between the obtained value of the target element and the standard limit value of that element, in this case the limits established by the CCME. The higher the index value, the higher the degree of pollution. It is estimated using Eq. (1):

$$
P i=\frac{C i}{S i}
$$

where $\mathrm{Pi}$ is the environmental pollution index of pollutant $\mathrm{i}$ for the soil, $\mathrm{Ci}$ is the concentration of soil heavy metal $\mathrm{i}$ and $\mathrm{Si}$ is the pollution limit. The statistical results of the Pi value for each heavy metal (both depths considered) are represented in Table 4 where only those heavy metals that exceeded permissible limits were evaluated. The single pollution index grading standards are provided in Table $3^{43}$.

The average $\mathrm{Pi}$ values for $\mathrm{Zn}, \mathrm{Pb}, \mathrm{Cd}$ and $\mathrm{Se}$ were less than two but more than one, revealing mild contamination. The mean Pi value for As was 3.291, indicating possible severe pollution in the study area.

Another index is the Nemerow Pollution Index (NPI), which gives us more information about the overall degree of contamination of the soil and includes the contents of all analysed heavy metals ${ }^{44,45}$. The NPI can be calculated using Eq. (2) as: 


\begin{tabular}{|l|l|l|}
\hline Level & Single pollution index $(\mathbf{P i})$ & Degree of pollution \\
\hline I & $\mathrm{Pi} \leq 1$ & Non pollution \\
\hline II & $1<\mathrm{Pi} \leq 2$ & Mild pollution \\
\hline III & $2<\mathrm{Pi} \leq 3$ & Moderately polluted \\
\hline IV & $\mathrm{Pi}>3$ & Severe pollution \\
\hline
\end{tabular}

Table 3. Single pollution index grading standards (adapted from Wang et al. ${ }^{43}$ ).

\begin{tabular}{|l|l|l|l|l|}
\hline \multirow{2}{*}{ Element } & Pi \\
\cline { 2 - 5 } & Minimum & Maximum & Average & Pollution degree (average) \\
\hline $\mathrm{Zn}$ & 1.023 & 2.187 & 1.866 & Mild \\
\hline $\mathrm{Pb}$ & 1.064 & 2.157 & 1.635 & Mild \\
\hline $\mathrm{As}$ & 2.631 & 3.951 & 3.291 & Severe \\
\hline $\mathrm{Cd}^{\mathrm{a}}$ & 1.312 & 1.312 & 1.312 & Mild \\
\hline $\mathrm{Se}$ & 1.059 & 3.106 & 1.671 & Mild \\
\hline Nemerow Pollution Index & 1.196 & \multicolumn{3}{|l|}{} \\
\hline
\end{tabular}

Table 4. Statistical analysis of the single pollution index (Pi) of each heavy metal surpassing the limits. ${ }^{\text {a Only }}$ one sample exceeded the CCME limits for this element.

\begin{tabular}{|l|l|l|}
\hline Class & NPI value & Quality of soil \\
\hline I & $<0.7$ & Clean \\
\hline II & $0.7-1$ & Warning limit \\
\hline III & $1-2$ & Slight pollution \\
\hline IV & $2-3$ & Moderate pollution \\
\hline V & $>3$ & Heavy pollution \\
\hline
\end{tabular}

Table 5. Nemerow Pollution Index soil classes (adapted from Kowalska et al. ${ }^{44}$ ).

$$
P I_{\text {Nemerow }}=\sqrt{\frac{\left(\frac{1}{n} \sum_{i-1}^{n} P I\right)^{2}+P I_{\text {max }}^{2}}{n}}
$$

where PI is the calculated values for the Single Pollution Index, $\mathrm{PI}_{\max }$ is the maximum value for the Single Pollution Index of all heavy metals and $n$ the number of heavy metals. Table 4 shows the value calculated for all the community gardens in Guelph in which certain elements exceeded the limits established for agricultural production in Canada. This index is a good indicator of total contamination because it highlights the most contaminated elements, is widely used, considers all individual elements, and has a precise scale. Table 5 presents five classes of soil quality based on the NPI ${ }^{44}$.

As shown at the bottom of Table 4, the Nemerow Index classifies contaminated soils in the community gardens as slightly polluted. Further study is required in order to understand completely those sites where the concentrations were higher and to determine the processes and possible long-term impacts on the nearby population.

\section{Conclusion}

In this study, we characterized heavy metals in community gardens from Guelph and investigated the potential health risks for vulnerable communities. Pollution evaluation and correlation with sociodemographic data were also carried out. The results showed that most average concentrations of elements analysed in garden soils of the city are lower than the Canadian soil quality guidelines for the protection of the environment and human health. However, $\mathrm{Zn}, \mathrm{Pb}, \mathrm{Se}, \mathrm{Cd}$ and $\mathrm{As}$ were found to be at higher concentrations than usual. In this region, the single pollution index of heavy metals showed that $\mathrm{Zn}, \mathrm{Pb}$, Se and $\mathrm{Cd}$ represent mild contamination, whilst As has a severe pollution degree. The Nemerow pollution index analysis which allows the assessment of the overall degree of pollution, suggested that community gardens in Guelph present slight contamination.

The high concentrations of heavy metals in some parts of the city are attributed mainly to past industrial activities, which have been documented previously. We have also characterized the spatial distribution of the patterns of heavy metals with GIS-based mapping tools which proved to be useful in improving the interpretation of the statistical output in tandem with sociodemographic information. Although many heavy metals were weakly associated with vulnerable populations, hotspots were mainly located in low-income areas of the city. Data provided shows that those hotspots tend to occur more in areas with low earning households, alternatively 
the same hotspots were not mainly located in zones with high number of immigrants and visible minorities. Similar results were obtained by Premji et al. ${ }^{46}$, their pollution measures were negatively correlated to income and no association was seen with visible minority and immigrant population. This shows diverse patterns of poverty and race, which could have several implications and may be the reason why little work has been done in the country on the relationship between contamination and vulnerable neighbourhoods.

Finally, special attention should be given to the constant monitoring of heavy metals and their relationship with vulnerable populations. Further local studies examining plant material and the pathway of these elements into human body are advised. While there remains limitations in this study, the outcomes provide critical data to better study the interconnection between pollution in urban agricultural areas and low income, racial inequality and many other factors that promote environmental injustice. Importance should also be given to the formulation of policies aiming to: (1) reduce the potential harm of heavy metals to humans and (2) constant monitoring of urban agricultural areas that might not be connected to community farming (such as privately-owned gardens where food is grown).

Received: 10 November 2020; Accepted: 5 May 2021

Published online: 28 May 2021

\section{References}

1. United Nations, Department of Economic and Social Affairs, P. D. World Urbanization Prospects: The 2018 Revision. World Urbanization Prospects: The 2018 Revision. https://population.un.org/wup/Publications/Files/WUP2018-KeyFacts.pdf (2018).

2. Kirkpatrick, S. I. \& Tarasuk, V. Food insecurity is associated with nutrient inadequacies among Canadian adults and adolescents. J. Nutr. 138, 604-612 (2008).

3. Heidary Monfared, S. Community Garden Heavy Metal Contamination Study. Environment Canada, Ecology Action Centre, 4-20 (2011).

4. He, Z. et al. Heavy metal contamination of soils: sources, indicators, and assessment. J. Environ. Indic. 9, 17-18 (2015).

5. Shayler, H., McBride, M. \& Harrison, E. Soil Contaminants and Best Practices for Healthy Gardens. http://cwmi.css.cornell.edu/ soilquality.htm (2009).

6. Alloway, B. J. Heavy Metals in Soils Trace Metals and Metalloids in Soils and Their Bioavailability. Environmental Pollution (Springer, 2013). https://doi.org/10.1007/978-94-007-4470-7_15.

7. Cheng, Z., Hettiarachchi, G. M. \& Kim, K. H. Urban soils research: SUITMA 10. J. Environ. Qual. 50, 2-6 (2020).

8. Clark, H. F., Brabander, D. J. \& Erdil, R. M. Sources, sinks, and exposure pathways of lead in urban garden soil. J. Environ. Qual. 35, 2066-2074 (2006).

9. Ferri, R. et al. Metal contamination of home garden soils and cultivated vegetables in the province of Brescia, Italy: implications for human exposure. Sci. Total Environ. 518-519, 507-517 (2015).

10. Qiao, M. et al. Characterization of soil heavy metal contamination and potential health risk in metropolitan region of northern China. Environ. Monit. Assess. 172, 353-365 (2011).

11. Wu, S. et al. Levels and health risk assessments of heavy metals in urban soils in Dongguan, China. J. Geochem. Explor. 148, 71-78 (2015).

12. Elreedy, S. et al. Relations between individual and neighborhood-based measures of socioeconomic position and bone lead concentrations among community-exposed men. The normative aging study. Am. J. Epidemiol. 150, 129-141 (1999).

13. Evans, G. W. \& Kantrowitz, E. Socioeconomic status and health: the potential role of environmental risk exposure. Annu. Rev. Public Health 23, 303-331 (2002).

14. Morrison, S., Fordyce, F. M. \& Scott, E. M. An initial assessment of spatial relationships between respiratory cases, soil metal content, air quality and deprivation indicators in Glasgow, Scotland, UK: relevance to the environmental justice agenda. Environ. Geochem. Health 36, 319-332 (2014).

15. Pasetto, R., Mattioli, B. \& Marsili, D. Environmental justice in industrially contaminated sites. A review of scientific evidence in the WHO European region. Int. J. Environ. Res. Public Health 16, 998 (2019).

16. Seay, D. Environmental Injustice: A Public Health Problem in Chattanooga. Honors Theses (University of Tennessee at Chattanooga, 2018).

17. Chakravartty, D. Attending to Differential Environmental Exposures Among Racialized Newcomer Women in Canada: Why so Difficult? ProQuest Dissertations and Theses (2019).

18. Masuda, J. R., Zupancic, T., Poland, B. \& Cole, D. C. Environmental health and vulnerable populations in Canada: mapping an integrated equity-focused research agenda. Can. Geogr. 52, 427-450 (2008).

19. Langlois, P., Smith, L., Fleming, S., Gould, R. \& Al, E. Blood lead levels in Toronto children and abatement of lead-contaminated soil and house dust. Arch. Environ. Health 51, 59-67 (1996).

20. Spelt, J. Urban Development in South-Central Ontario (McGill-Queen's University Press, 1972).

21. McKeague, J. A., Desjardins, J. G. \& Wolynetz, M. S. Minor Elements in Canadian Soils. Agriculture Canada., Ottawa, LRRI Publ. 27 (1979).

22. Kaiser, M. L., Williams, M. L., Basta, N., Hand, M. \& Huber, S. When vacant lots become urban gardens: characterizing the perceived and actual food safety concerns of urban agriculture in Ohio. J. Food Prot. 78, 2070-2080 (2015).

23. Huang, G. \& London, J. Mapping cumulative environmental effects, social vulnerability, and health in the San Joaquin Valley, California. Am. J. Public Health 102, 830-832 (2012).

24. Cornell Waste Management Institute. Healthy Soils, Healthy Communities Metals in Urban Garden Soils. https://ecommons.corne ll.edu/handle/1813/48147 (2015).

25. Jung, M. C. \& Thornton, I. Environmental contamination and seasonal variation of metals in soils, plants and waters in the paddy fields around a Pb-Zn mine in Korea. Sci. Total Environ. 198, 105-121 (1997).

26. Boulding, J. R. Description and Sampling of Contaminated Soils. A Field Guide (Lewis Publishers, 1994). https://doi.org/10.1201/ 9781315140926.

27. Hoffman, D. W. Soil Survey of Wellington County, Ontario (Research Branch, Canada Department of Agriculture, 1963).

28. Impellitteri, C. A., Lu, Y., Saxe, J. K., Allen, H. E. \& Peijnenburg, W. J. G. M. Correlation of the partitioning of dissolved organic matter fractions with the desorption of $\mathrm{Cd}, \mathrm{Cu}, \mathrm{Ni}, \mathrm{Pb}$ and $\mathrm{Zn}$ from $18 \mathrm{Dutch}$ soils. Environ. Int. 28, 401-410 (2002).

29. Statistics Canada. Data Products, 2016 Census, 2016. https://www12.statcan.gc.ca/census-recensement/2016/dp-pd/indexeng. cfm (2017).

30. Canadian Council of Ministers of the Environment. Canadian Environmental Quality Guidelines Canadian Council of Ministers of the Environment. http://ceqg-rcqe.ccme.ca/en/index.html\#void (1999).

31. Ramos, S. J. et al. Rare Earth elements in the soil environment. Curr. Pollut. Rep. 2, 28-50 (2016). 
32. Ontario Geological Survey. Mineral Deposit Inventory (MDI) Database. Geology of Ontario. Ministry of Energy, Northern Development and Mines. http://www.geologyontario.mndm.gov.on.ca/MDI_Description.html (2020).

33. Plum, L. M., Rink, L. \& Hajo, H. The essential toxin: impact of zinc on human health. Int. J. Environ. Res. Public Health 7, 1342-1365 (2010).

34. Smolders, E., Brans, K., Földi, A. \& Merckx, R. Cadmium fixation in soils measured by isotopic dilution. Soil Sci. Soc. Am. J. 63, 78-85 (1999).

35. Zhang C. B. et al. Characteristics of spatial variability of soil heavy metal concentrations in contaminated sites and their implications for source identification (In Chinese). Soils. 38(5) 525-533 (2006).

36. Zhang, C., Wu, L., Luo, Y., Zhang, H. \& Christie, P. Identifying sources of soil inorganic pollutants on a regional scale using a multivariate statistical approach: role of pollutant migration and soil physicochemical properties. Environ. Pollut. 151, 470-476 (2008).

37. Agency for Toxic Substances and Disease Registry. Toxicological profile for Cadmium. In U.S. Department of Health and Human Services, Public Health Service (CRC Press, 2012).

38. World Health Organization. Lead Poisoning and Health (World Health Organization). https://www.who.int/news-room/fact-sheets/ detail/lead-poisoning-and-health (2019).

39. Sadiq, M. Arsenic chemistry in soils: an overview of thermodynamic predictions and field observations. Water Air Soil Pollut. 93, 117-136 (1997).

40. UNICEF. Arsenic Primer. Guidance on the Investigation \& Mitigation of Arsenic Contamination. United Nations Children's Fund (UNICEF), World Heatlh Organisation (WHO). http://www.unicef.org/wes (2018).

41. Uttam, S., Fayiga, A. \& Sonon, L. Selenium in the soil-plant environment: a review. Int. J. Appl. Agric. Sci. 3, 1-18 (2017).

42. Kabata-Pendias, A. \& Pendias, H. Trace Elements in Soils and Plants: Fourth Edition. Trace Elements in Soils and Plants, Third Edition (CRC Press, 2001). https://doi.org/10.1201/b10158.

43. Wang, X., Sun, Y., Li, S. \& Wang, H. Spatial distribution and ecological risk assessment of heavy metals in soil from the Raoyanghe Wetland, China. PLoS ONE 14, e0220409 (2019).

44. Premji, S., Bertrand, F., Smargiassi, A. \& Daniel, M. Socio-economic correlates of municipal-level pollution emissions on Montreal Island. Can. J. Public Heal. 98, 138-142 (2007).

45. Qingjie, G., Jun, D., Yunchuan, X., Qingfei, W. \& Liqiang, Y. Calculating pollution indices by heavy metals in ecological geochemistry assessment and a case study in parks of Beijing. J. China Univ. Geosci. 19(3), 230-241. https://doi.org/10.1016/S1002-0705(08) 60042-4 (2008).

46. Kowalska, J. B., Mazurek, R., Gąsiorek, M. \& Zaleski, T. Pollution indices as useful tools for the comprehensive evaluation of the degree of soil contamination-a review. Environ. Geochem. Health 40, 2395-2420 (2018).

\section{Acknowledgements}

This study was made possible with funding from Natural Science and Engineering Research Council (NSERC) of Canada Discovery Grant (RGPIN-2014-4100) and Mitacs Inc. Globalink Program. This project could not have been completed without the participation and support of community garden coordinators and Samatha Dupré from the City of Guelph who provided administrative guidance. The authors are grateful to Monica Fontes and Elaina Greaves for their help during soil sampling and analysis and Helen Lalande for heavy metal analysis.

\section{Author contributions}

F.M.-L. collected samples, analyzed them in laboratory, analyzed data, wrote manuscript. A.B. supervision, funding acquisition, manuscript editing.

\section{Competing interests}

The authors declare no competing interests.

\section{Additional information}

Supplementary Information The online version contains supplementary material available at https://doi.org/ 10.1038/s41598-021-90368-3.

Correspondence and requests for materials should be addressed to A.B.

Reprints and permissions information is available at www.nature.com/reprints.

Publisher's note Springer Nature remains neutral with regard to jurisdictional claims in published maps and institutional affiliations.

(c) (i) Open Access This article is licensed under a Creative Commons Attribution 4.0 International License, which permits use, sharing, adaptation, distribution and reproduction in any medium or format, as long as you give appropriate credit to the original author(s) and the source, provide a link to the Creative Commons licence, and indicate if changes were made. The images or other third party material in this article are included in the article's Creative Commons licence, unless indicated otherwise in a credit line to the material. If material is not included in the article's Creative Commons licence and your intended use is not permitted by statutory regulation or exceeds the permitted use, you will need to obtain permission directly from the copyright holder. To view a copy of this licence, visit http://creativecommons.org/licenses/by/4.0/.

(C) The Author(s) 2021 